\title{
Mucinous and Nonmucinous Appendiceal Adenocarcinomas: Different Clinicopathological Features but Similar Genetic Alterations
}

Wareef Kabbani, M.D., Patrick S. Houlihan, Rajayalaksh Luthra, Ph.D., Stanley R. Hamilton, M.D., Asif Rashid, M.D., Ph.D.

Department of Pathology, University of Texas M. D. Anderson Cancer Center, Houston, Texas

The genetic alterations of appendiceal carcinomas have not been reported in detail. We studied the clinicopathological factors and genetic alterations including microsatellite instability, p53 overexpression, and mutations of the $K$-ras proto-oncogene of 30 appendiceal adenocarcinomas, consisting of 23 mucinous and 7 nonmucinous carcinomas. Sixteen $(70 \%)$ mucinous carcinomas presented with pseudomyxoma peritonei, but 6 of 7 (86\%) nonmucinous carcinomas presented with appendicitis $(P=\mathbf{. 0 0 2})$. All carcinomas were microsatellite stable, and p53 overexpression was present in only 1 of $30(3 \%)$ carcinomas. $K$-ras mutation was present in 11 of $20(55 \%)$ carcinomas, including 8 of $16(50 \%)$ mucinous and 3 of $4(75 \%)$ nonmucinous carcinomas. The mean survival of patients with mucinous carcinomas was $26 \pm 19$ months compared with $13 \pm 9$ months for patients with nonmucinous carcinomas $(P=.0002)$. Our findings suggest that mucinous and nonmucinous carcinomas of appendix have similar genetic alterations, but different clinical presentation and prognosis.

KEY WORDS: Adenocarcinoma, Appendix, K-ras, Microsatellite instability, p53.

Mod Pathol 2002;15(6):599-605

Appendiceal carcinoma is an uncommon malignancy of the gastrointestinal tract with a prevalence ranging from 0.2 to $0.3 \%$ of appendectomy specimens $(1,2)$. Most appendiceal carcinomas arise from an adenomatous polyp or serrated adenoma (3-5) and present clinically with pseudomyxoma peritonei.

Most colorectal cancers develop from adenomatous polyps, and morphological and genetic pro-

Copyright (C) 2002 by The United States and Canadian Academy of Pathology, Inc.

VOL. 15, NO. 6, P. 599, 2002 Printed in the U.S.A.

Date of acceptance: January 8, 2002.

Address reprint requests to: Asif Rashid, M.D., Ph.D., Department of Pathology, Box 85, M. D. Anderson Cancer Center, 1515 Holcombe Boulevard, Houston, TX; fax: 713-792-5531. gression in an adenoma-adenocarcinoma sequence and in hereditary colorectal cancer syndromes are well described (6-9). The majority of colorectal cancers have truncating mutations or deletions of the adenomatous polyposis coli ( $A P C$ ) gene on chromosome $5 \mathrm{q}$ or mutations of the $\beta$-catenin gene. Point mutations of the $K$-ras protooncogene and mutations and/or deletions of the p53 gene on chromosome $17 \mathrm{p}$ are also common. In a second pathway to colorectal neoplasia, microsatellite instability (MSI; also termed DNA replication errors and ubiquitous somatic mutations) is caused by mutations in a nucleotide mismatch repair gene, including $h M S H 2, h M L H 1, P M S 1, P M S 2$, and GTBP $(6-9)$. MSI is characterized by additions and deletions of nucleotides in numerous repeated nucleotide sequences (microsatellites). MSI is frequent in the right-sided colon carcinomas and mucinous colorectal carcinomas (6-9).

The genetic alterations in appendiceal carcinoma have not been reported in detail. We therefore studied MSI, p53 overexpression, and $K$-ras mutations in appendiceal carcinomas and compared these genetic alterations with the clinicopathologic findings.

\section{MATERIALS AND METHODS}

\section{Case Material}

A computer search of MD Anderson Cancer Center surgical pathology diagnoses from 1995 through 2000 was performed. Primary appendiceal carcinomas were identified using the World Health Organization classification of appendiceal carcinomas (10). There were 30 patients with primary appendiceal carcinomas and available paraffin-embedded blocks. Neuroendocrine tumors were excluded. The patient records and histopathological findings were reviewed. Primary site in the appendix was verified by histology in 18 cases and by report of an outside institution in the remaining 12 cases. Familial history of appendiceal or colorectal carcinoma was not present in any patient. 


\section{DNA Preparation}

Genomic DNA was extracted separately from appendiceal carcinoma and control nonlesional appendiceal or colorectal tissue by microdissection from paraffin-embedded blocks, as described in previous studies (11).

\section{Microsatellite Markers and Polymerase Chain Reaction Amplification}

Fluorescent-labeled polymerase chain reaction (PCR) amplification was performed using the markers recommended by the National Cancer Institute workshop (12). The fluorescent dye-labeled and unlabeled primers were obtained (Life Technologies, Gaithersburg, MD). The 5' oligonucleotide was end labeled with 6-FAM (BAT-25, D17S250), TET (BAT-26, D2S123), or HEX (D5S346) fluorescent dye. PCR was performed with 40 ng of DNA in reaction mix consisting of $1 \times$ GeneAmp PCR Gold buffer (Applied Biosystems, Foster City, CA), $2.5 \mathrm{~mm}$ of $\mathrm{MgCl}_{2}, 200 \mu \mathrm{M}$ of dNTPs, $0.83 \mu \mathrm{M}$ of each primer, and $2 \mathrm{U}$ of AmpliTaq Gold DNA polymerase (Applied Biosystems) in a final volume of $15 \mu \mathrm{L}$. PCR was performed using a GENEAMP PCR system 9700 (Applied Biosystems) with the following conditions: $95^{\circ} \mathrm{C}$ for 7 minutes; 3 cycles at $94^{\circ} \mathrm{C}$ for 1 minute, $58^{\circ} \mathrm{C}$ for 30 seconds, and $72^{\circ} \mathrm{C}$ for 45 seconds; 42 cycles at $93^{\circ} \mathrm{C}$ for 45 seconds, $54^{\circ} \mathrm{C}$ for 30 seconds, and $72^{\circ} \mathrm{C}$ for 40 seconds; and final extension at $72^{\circ} \mathrm{C}$ for 10 minutes. A $0.25-\mu \mathrm{L}$ aliquot of each fluorescent-labeled PCR product was analyzed on an ABI 310 Genetic Analyzer using GeneScan Analysis software (Applied Biosystems). Each sample included GeneScan 500 (TAMARA) size standard for accurate size calling.

\section{Microsatellite Instability}

The presence of MSI was determined from the PCR amplifications of the two mononucleotide markers (BAT-25 and BAT-26) and three dinucleotide markers (D2S123, D5S346, D17S250; 12). Mononucleotide markers (BAT-25 and BAT-26) were used to assess MSI in specimens without nonlesional DNA. Specimens with high levels of MSI (MSI-H) were defined by shifts of bands as compared with the control DNA in $\geq 40 \%$ of evaluable markers, and low levels of MSI (MSI-L), by shifts in $<40 \%$ of evaluable microsatellite markers.

\section{Immunohistochemistry for p53 Overexpression}

Immunohistochemistry with mouse monoclonal antibody D07 (1:250 dilution) and standard techniques including antigen retrieval was used to determine p53 gene product overexpression as in our previous studies (13). Overexpression of p53 was considered to be present when $>50 \%$ of the nuclei of tumor cells stained by immunohistochemistry.

\section{DNA Sequencing of $K$-ras}

Exon 1 of $K$-ras gene was amplified by PCR as previously described (14). PCR reaction was performed in a $50-\mu \mathrm{L}$ volume using PCR Master (Roche Diagnostics Corporation, Indianapolis, IN) and 1 $\mu \mathrm{M}$ of 5 ' and 3' primers, with initial denaturation at $95^{\circ} \mathrm{C}$ for 5 minutes; 40 cycles at $94^{\circ} \mathrm{C}$ for 1 minute, $58^{\circ} \mathrm{C}$ for 1 minute, and $72^{\circ} \mathrm{C}$ for 2 minutes; and a final extension cycle at $72^{\circ} \mathrm{C}$ for 10 minutes. The PCR products were treated with shrimp alkaline phosphatase and exonuclease I (United States Biochemical, Cleveland, $\mathrm{OH}$ ) and sequenced using the BigDye Terminator Cycle Sequencing Ready Reaction Kit (Applied Biosystems) with internal primer. The sequence reactions were run on an Applied Biosystems 3700 Genetic Analyzer (Applied Biosystems). The data were collected and analyzed using Applied Biosystems sequencing analysis software (Applied Biosystems), according to the manufacturer's protocols. Each mutation was verified by sequencing in both directions.

\section{Clinicopathological Correlation}

The K-ras mutation status was compared with the clinical-and pathologic parameters, including age and sex of patients; histological type, grade, and stage of carcinoma; presence of pseudomyxoma peritonei; association with appendiceal adenoma; rupture of appendix; and treatment and follow-up status.

\section{Statistical Analysis}

The clinicopathological associations were compared with histological type of carcinomas and $K$-ras mutation status using chi-square, Fisher's exact, ornonpaired $t$ test. The overall survival time and disease-free survival of patients with mucinous and nonmucinous carcinomas was compared by the Kaplan and Meier method (15) by using SPSS for Windows software (SPSS Inc., Chicago, IL).

\section{RESULTS}

\section{Clinicopathologic Factors}

The clinicopathologic findings are summarized in Table 1. Twenty-three of 30 patients (77\%) had a mucinous adenocarcinoma, including 22 with a low-grade mucinous adenocarcinoma (Fig. 1) and 1 with mucinous adenocarcinoma with focal signetring cells comprising $<50 \%$ of the tumor. Seven (23\%) patients had nonmucinous gland-forming adenocarcinoma (Fig. 2), including one with focal 
signet ring cell morphology (Fig. 3). Six of 7 (86\%) nonmucinous carcinomas were moderate or poorly differentiated, but all 23 mucinous carcinomas were well differentiated $(P=.00001$; Table 1$)$.

Patients with mucinous and nonmucinous carcinomas had different clinical presentation and sites of metastatic disease. Sixteen of $23(70 \%)$ mucinous carcinomas presented with pseudomyxoma peritonei, but 6 of 7 (86\%) nonmucinous carcinomas presented with appendicitis $(P=.002$; Table 1$)$. Similarly, omental metastases were present in 16 of 23 (62\%) mucinous carcinomas, but none of 7 nonmucinous carcinomas $(P=.002)$. In contrast, liver or lung metastasis was present in 3 of 7 (43\%) nonmucinous carcinomas, but in none of 17 mucinous carcinomas $(P=.01)$.

Patients with mucinous carcinoma had a better overall survival and disease-free survival. The mean overall survival of patients with mucinous carcinomas was $26 \pm 19$ months, compared with $13 \pm 9$ months for nonmucinous carcinomas (Fig. 4A; $P=$ .0002). The mean disease-free survival of patients with mucinous carcinomas was $18 \pm 3$ months, compared with $7 \pm 4$ months for nonmucinous carcinomas (Fig. 4B; $P=.04$ ).

\section{Genetic Alterations}

Allelic shift was present in none of 30 carcinomas by mononucleotide markers (BAT-25 or BAT-26), nor in any of 19 carcinomas by dinucleotide markers (D2S123, D5S346, and D17S250). Thus, all carcinomas were classified as microsatellite stable.

p53 overexpression was present in only one moderately differentiated nonmucinous adenocarcinoma.

TABLE 1. Clinicopathological Associations of Appendiceal Carcinomas

\begin{tabular}{|c|c|c|c|c|}
\hline Associated Factor & $\begin{array}{c}\text { Total } \\
(n=30)\end{array}$ & $\begin{array}{l}\text { Mucinous } \\
(n=23)\end{array}$ & $\begin{array}{c}\text { Nonmucinous } \\
\quad(n=7)\end{array}$ & $P$ Value \\
\hline Age in y (mean \pm SD) & $56 \pm 12$ & $56 \pm 13$ & $57 \pm 10$ & NS \\
\hline Gender (F/M) & 1.3 & 1.3 & 1.3 & NS \\
\hline \multicolumn{5}{|l|}{ Clinical Presentation } \\
\hline PMP & $16(53)$ & $16(70)$ & 0 & 0.002 \\
\hline $\begin{array}{l}\text { Abdominal } \\
\text { pain/appendicitis }\end{array}$ & $7(23)$ & $1(4)$ & $6(86)$ & 0.00008 \\
\hline Mass & $3(10)$ & $2(9)$ & $1(14)$ & \\
\hline Others $^{a}$ & $4(13)$ & $4(17)$ & 0 & \\
\hline \multicolumn{5}{|l|}{ Treatment modality } \\
\hline Appendectomy & $12(40)$ & & $4(57)$ & \\
\hline Right hemicolectomy & $12(40)$ & $7(30)$ & $5(71)$ & \\
\hline Cytoreduction (debulking) & $19(63)$ & $19(83)$ & 0 & 0.0002 \\
\hline \multicolumn{5}{|l|}{ Chemotherapy } \\
\hline $\begin{array}{l}\text { Differentiation } \\
\text { Well } \\
\text { Moderately or poorly }\end{array}$ & $\begin{aligned} 24 & (80) \\
6 & (20)\end{aligned}$ & & $\begin{array}{l}1(14) \\
6(86)\end{array}$ & 0.00001 \\
\hline \multicolumn{5}{|l|}{ Appendiceal adenoma } \\
\hline Present & $7(23)$ & $4(17)$ & $3(43)$ & NS \\
\hline Absent & $6(20)$ & $5(22)$ & $1(14)$ & \\
\hline Not assessed & $17(57)$ & $14(61)$ & $3(43)$ & \\
\hline \multicolumn{5}{|l|}{ Rupture of the appendix } \\
\hline Present & $10(33)$ & $7(30)$ & - $3(43)$ & NS \\
\hline Absent & $7(23)$ & $4(17)$ & $3(43)$ & \\
\hline Not assessed & $13(43)$ & $12(52)$ & $1(14)$ & \\
\hline \multicolumn{5}{|l|}{ Stage } \\
\hline I & 0 & 0 & 0 & NS \\
\hline II & $2(7)$ & $1(4)$ & $1(14)$ & \\
\hline III & $2(7)$ & $1(4)$ & $1(14)$ & \\
\hline IV & $26(86)$ & $21(91)$ & $5(72)$ & \\
\hline \multicolumn{5}{|l|}{ Metastatic sites } \\
\hline Omentum & $16(62)$ & $16(70)$ & 0 & 0.002 \\
\hline Liver & $3(10)$ & 0 & $3(43)$ & 0.01 \\
\hline Lung & $3(10)$ & 0 & $3(43)$ & 0.01 \\
\hline Spleen & $5(17)$ & $5(22)$ & 0 & \\
\hline Ovary & $5(17)$ & $3(13)$ & $2(29)$ & \\
\hline Uterus & $3(10)$ & $1(4)$ & $2(29)$ & \\
\hline Skin & $1(3)$ & $1(4)$ & 0 & \\
\hline \multicolumn{5}{|l|}{ Vital status } \\
\hline ANED & 3 & 2 & 1 & NA \\
\hline AWD & 21 & 19 & 2 & \\
\hline DOD & 4 & $1^{b}$ & 3 & \\
\hline LFU & 2 & 1 & 1 & \\
\hline Survival in mo (mean $\pm \mathrm{SD}$ ) & $24 \pm 18$ & $26 \pm 19$ & $13 \pm 9$ & 0.0002 \\
\hline
\end{tabular}

Data in first three columns are $n$ (\%) unless otherwise indicated. ANED, alive with no evidence of disease; AWD, alive with disease; DOD, dead of disease; F, female; M, male; NA, not applicable; NS, not significant; PMP, pseudomyxoma peritonei.

${ }^{a}$ Bowel obstruction, ureteral obstruction, pulmonary metastasis, abnormal pelvic ultrasound.

${ }^{b}$ Mucinous carcinoma with signet-ring features. 


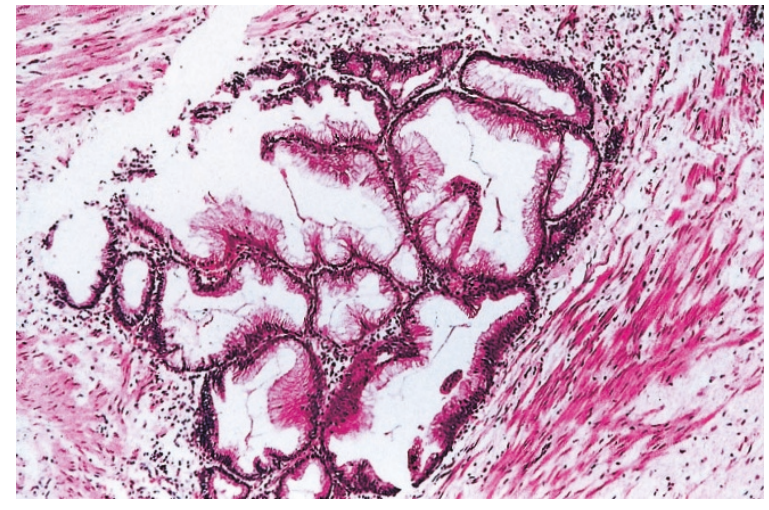

FIGURE 1. Low-grade mucinous adenocarcinoma of the appendix. $(\times 200)$.

K-ras mutations were present in 11 of 20 (55\%) carcinomas. $K$-ras mutations were present in codon 12 of the K-ras gene in 9 of $20(45 \%)$ carcinomas and in codon 13 in two of $20(10 \%)$ carcinomas (Fig. 5). The most frequent mutation was substitution of aspartic acid for glycine caused by $\mathrm{G}$ to A transition at codon 12 (GGT to GAT), which was present in 7 carcinomas. Other mutations were substitution of valine for glycine at codon 12 caused by $\mathrm{G}$ to $\mathrm{T}$ transversion in two carcinomas (GGT to GTT), and substitution of aspartic acid for glycine at codon 13 caused by G to A transition in two carcinomas (GGC to GAC). K-ras mutation was present in 8 of 16 (50\%) mucinous carcinomas and in 3 of 4 (75\%) nonmucinous carcinomas. There was no significant association of $K$-ras mutation with the clinicopathological characteristics of the tumor or patient (Table 2).

\section{DISCUSSION}

In this study, mucinous and nonmucinous carcinomas of the appendix had different clinical presentation and survival, but both subtypes of carcinomas lacked MSI or p53 overexpression and had frequent $K$-ras mutations. In contrast, colorectal

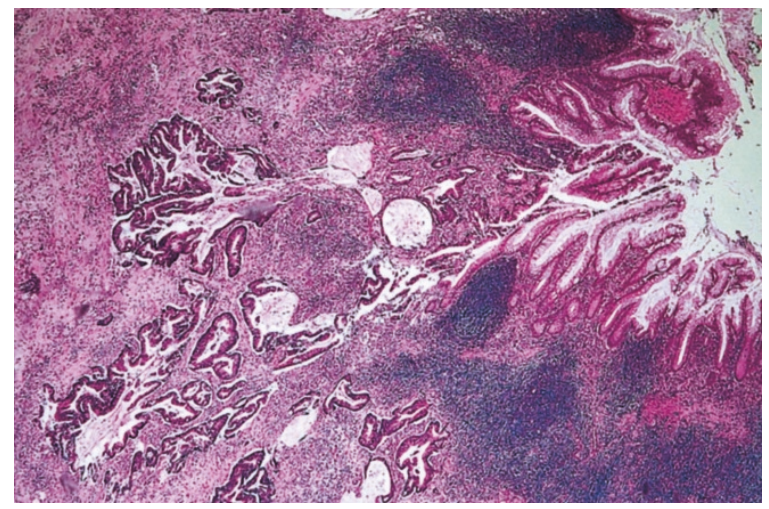

FIGURE 2. Moderately differentiated nonmucinous adenocarcinoma of the appendix $(\times 100)$.

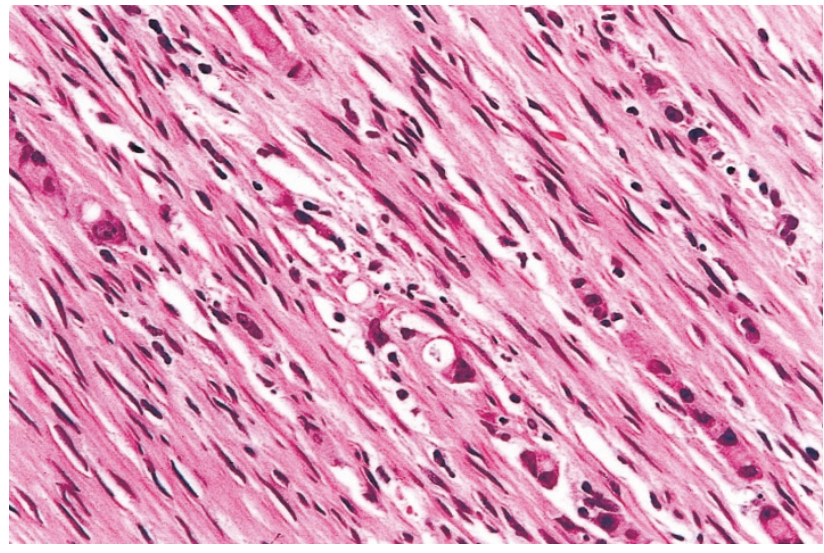

FIGURE 3. Signet ring cell carcinoma of the appendix $(\times 400)$.

carcinomas have frequent p53 overexpression, and right-sided colon carcinomas and/or mucinous histological type of colon carcinomas frequently have high levels of MSI (6-9). The frequency of $K$-ras mutation is similar in appendiceal and colorectal carcinomas, but the molecular pathogenesis differs. $K$-ras mutation was present in $55 \%$ of appendiceal carcinomas in our study. In addition, $K$-ras mutations were frequent in mucinous and nonmucinous carcinomas in our study. Similarly, previous studies have also reported frequent $K$-ras mutations in appendiceal tumors associated with pseudomyxoma peritonei $(16,17)$. In contrast, appendiceal carcinoid tumors, including those with mucinous-goblet cell differentiation, lack $K$-ras mutations (18).

p53 overexpression was infrequent, as it was present in only one carcinoma in our study. This is corroborated by lack of allelic loss of $17 \mathrm{p}$, the chromosomal location of the p53 gene in tumors associated with pseudomyxoma peritonei in a previous study (17). Similarly, appendiceal carcinoid tumors have infrequent $p 53$ gene mutations $(19,20)$.

In our study, all the carcinomas had microsatellite stable genotype. In contrast, occasional allelic shift in a few appendiceal tumors with pseudomyxoma peritonei has been reported in a previous study (17), and colorectal cancer with mucinous histology has high levels of MSI.

Most of the appendiceal carcinomas were associated with an appendiceal adenoma and/or rupture of appendix. An adenoma-carcinoma sequence exists in the appendix that is similar to the one described in the colorectum (3-5). This is further corroborated by the presence of occasional appendiceal carcinomas in patients with familial adenomatous polyposis syndrome $(21,22)$. In this study, the frequency of appendiceal adenomas was similar in both mucinous and nonmucinous types. The prevalence of adenoma in our study is likely an underestimate because of extensive replacement of 

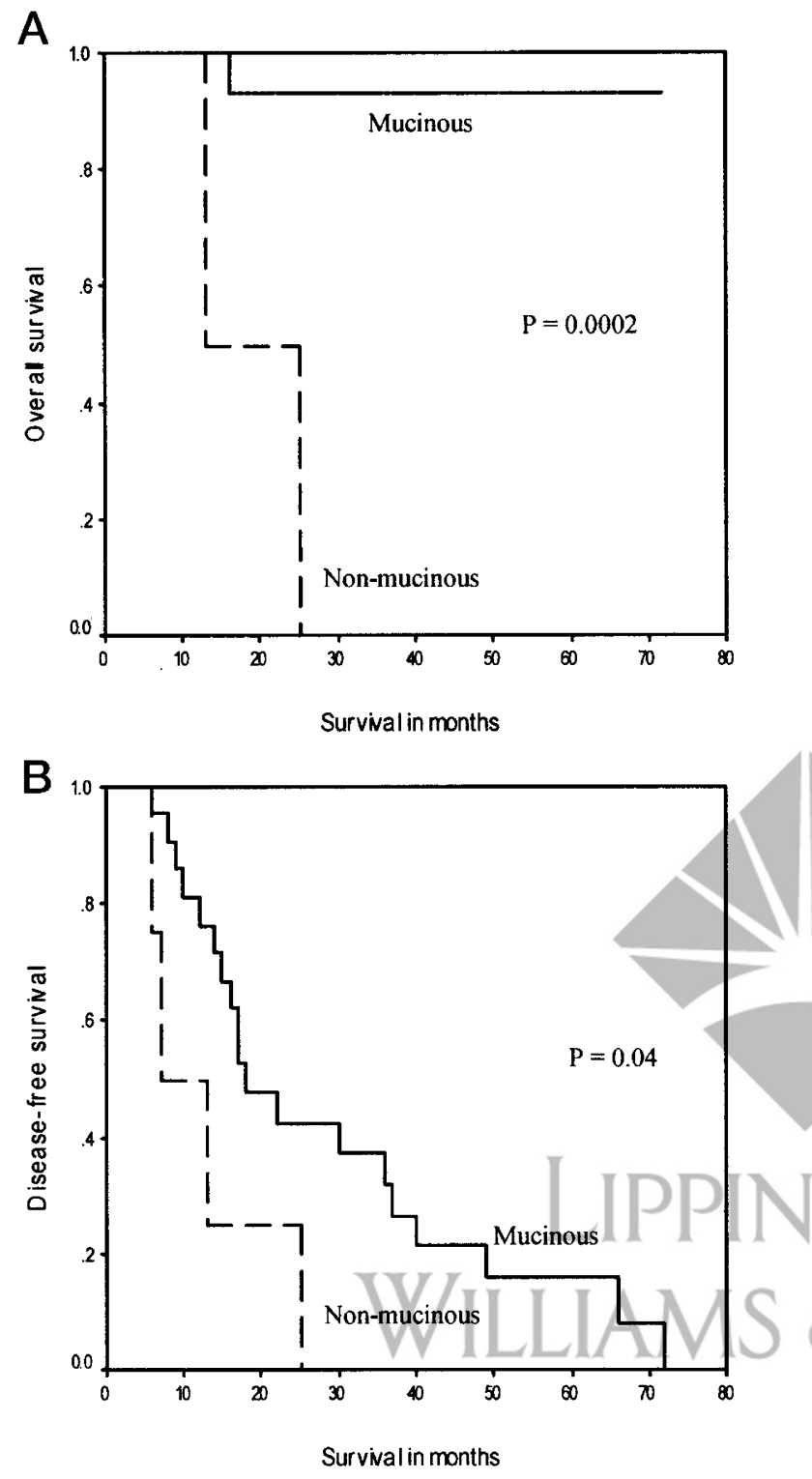

FIGURE 4. Kaplan-Meier curve showing overall (A) and disease-free (B) survival analysis of mucinous and nonmucinous appendiceal carcinoma.

adenoma by carcinoma; undersampling of adjacent, grossly normal appendiceal tissue; or unavailability of slides from source institutions for review.

The clinical presentation of appendiceal tumors differs by the histological type of cancer. Most patients with mucinous adenocarcinomas presented with pseudomyxoma peritonei. On the other hand, most nonmucinous carcinomas presented with appendicitis or acute abdomen. The origin and histological classification of pseudomyxoma peritonei is controversial $(16,17,23-39)$. Recent studies suggest that most cases of pseudomyxoma peritonei are caused by appendiceal mucinous tumors $(17,23)$. Ronnett et al. (24) have classified patients with pseudomyxoma peritonei into two categories: disseminated peritoneal
GT A GT TG G $\mathrm{A}$ G CT G GT G G GT AG G C A AG A
40

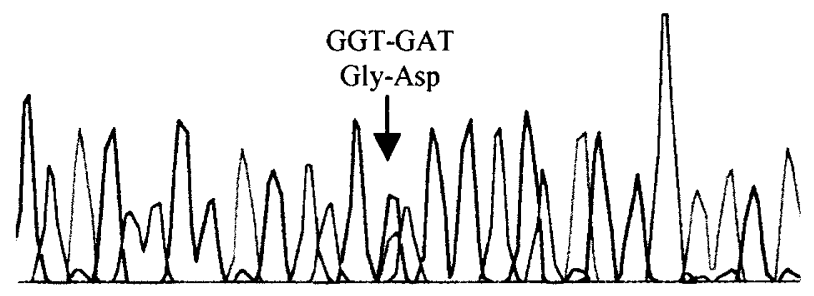

$$
\begin{array}{r}
\text { TA GTTGG A } \\
40
\end{array}
$$

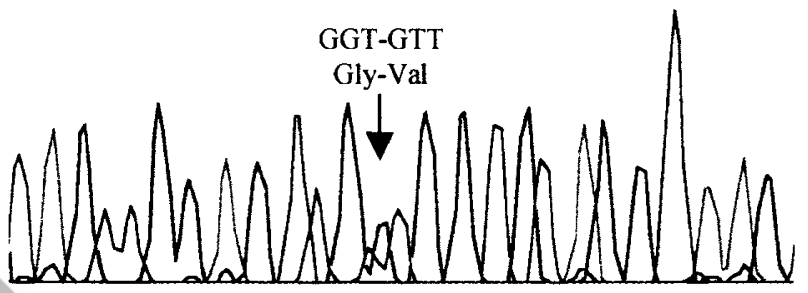

FIGURE 5. K-ras sequencing of appendiceal carcinomas. The mutations are indicated by arrows. The top panel shows a GGT (glycine) to GAT (aspartic acid) and the lower panel shows a GGT (glycine) to GTT (valine) point mutations at codon 12 of K-ras gene.

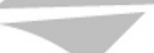

adenomucinosis and peritoneal mucinous carcinomatosis. Disseminated peritoneal adenomucinosis, also referred to by others (39) as dissecting mucin containing atypical epithelium, is characterized by peritoneal lesions composed of abundant extracellular mucin containing scant simple to focally proliferative mucinous epithelium with little cytological atypia or mitotic activity. In contrast, peritoneal mucinous carcinomatosis is characterized by peritoneal lesions composed of more abundant mucinous epithelium with the architectural and cytological features of carcinoma. The clinical course of adenomucinosis is protracted (for many years), with a good response to debulking and other modalities of treatment; death is usually due to complications of treatment (38). On the other hand, prognosis of adenocarcinomatosis is generally worse, with shorter survival (40). However, some patients show histological progression from one surgery to the next and die of their disease despite better histology $(24,40)$. In our study, the mucinous carcinomas either showed invasion or had dysplastic epithelium, and most of our specimens were from a second operation. Our mucinous carcinomas would be classified as peritoneal mucinous carcinomatosis according to criteria used by Ronnett et al. (24).

The survival was also dependent on the histological type of carcinoma, although only four patients died of disease in our series, with limited follow-up, including three with nonmucinous carcinomas and one with focal signet-ring differentiation. This sug- 


\begin{tabular}{|c|c|c|c|}
\hline Clinicopathological Parameters & $\begin{array}{l}\text { K-ras Mutation Present } \\
\qquad(n=11)\end{array}$ & $\begin{array}{l}\text { K-ras Mutation Absent } \\
\qquad(n=9)\end{array}$ & $P$ Value \\
\hline Age in $y$ (mean \pm SD) & $55 \pm 11$ & $60 \pm 12$ & NS \\
\hline $\mathrm{F} / \mathrm{M}$ & 2 & 1.5 & NS \\
\hline \multicolumn{4}{|l|}{ Presentation } \\
\hline PMP & $4(36)$ & $6(66)$ & \multirow[t]{3}{*}{ NS } \\
\hline $\begin{array}{l}\text { Abdominal pain and/or } \\
\text { appendicitis }\end{array}$ & $2(18)$ & $2(22)$ & \\
\hline Others & $5(45)$ & $1(11)$ & \\
\hline \multicolumn{4}{|l|}{ Histopathological type } \\
\hline Mucinous & $8(73)$ & $8(83)$ & \multirow[t]{2}{*}{ NS } \\
\hline Nonmucinous & $3(27)$ & $1(17)$ & \\
\hline \multicolumn{4}{|l|}{ Differentiation } \\
\hline Well & $9(82)$ & $8(83)$ & \multirow[t]{2}{*}{ NS } \\
\hline Moderately or poorly & $2(18)$ & $1(17)$ & \\
\hline \multicolumn{4}{|l|}{ Stage } \\
\hline I & 0 & 0 & \multirow[t]{4}{*}{ NS } \\
\hline II & $2(18)$ & 0 & \\
\hline III & $2(18)$ & 0 & \\
\hline IV & $7(64)$ & $9(100)$ & \\
\hline \multicolumn{4}{|l|}{ Appendiceal adenoma } \\
\hline Present & $3(27)$ & $2(22)$ & \multirow[t]{3}{*}{ NS } \\
\hline Absent & $4(36)$ & $3(33)$ & \\
\hline Not assessed & $4(36)$ & $4(44)$ & \\
\hline \multicolumn{4}{|l|}{ Rupture of the appendix } \\
\hline Present & $3(27)$ & $2(22)$ & \multirow[t]{3}{*}{ NS } \\
\hline Absent & $2(18)$ & $3(33)$ & \\
\hline Not assessed & $6(55)$ & $4(44)$ & \\
\hline \multicolumn{4}{|l|}{ Vital status } \\
\hline ANED & 3 & 0 & \multirow[t]{4}{*}{ NA } \\
\hline AWD & & 8 & \\
\hline DOD & 1 & 0 & \\
\hline LFU & 1 & 1 & \\
\hline Survival in mo (mean \pm SD) & $26 \pm 18$ & $24 \pm 14$ & NS \\
\hline
\end{tabular}

Data in first three columns are $n$ (\%) unless otherwise indicated. ANED, alive with no evidence of disease; AWD, alive with disease; LFU, lost to follow-up; F, female; M, male; NA, not applicable; NS, not significant.

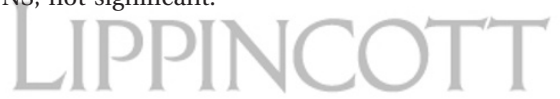

gests that the nonmucinous carcinomas or signetring cell carcinomas are aggressive neoplasms in contrast to mucinous carcinomas. Better prognosis of mucinous carcinomas has been reported $(41,42)$.

Limited data are available from the literature on molecular genetic alterations in mucinous appendiceal carcinomas (10). K-ras mutations and loss of chromosomal arms including 3p, 5q22, 6q, 17p13, and 18q21 have been reported in mucinous carcinomas to support clonality of separate foci but were not correlated with a clinical outcome $(16,17,43$, 44). In contrast, molecular genetic alterations and clinical behavior of nonmucinous appendiceal carcinomas have not been reported in the literature. Cytogenetic analysis, comparative genomic hybridization, genome-wide allelotyping, and microarray technology can help in further molecular characterization of these carcinomas. Xenografts or tissue culture can help in getting abundant amount of enriched tumor samples for these studies, which is a major problem for mucinous carcinomas.

In summary, genetic alterations in appendiceal carcinomas differ from colorectal carcinomas and consist of frequent K-ras proto-oncogene mutation but not alterations of p53 tumor suppressor gene or MSI genotype. The clinical presentation and overall survival differs between mucinous and nonmucinous carcinomas.

\section{REFERENCES}

1. Hananel N, Powsner E, Wolloch Y. Adenocarcinoma of the appendix: an unusual disease. Eur J Surg 1998;164:859-62.

2. Nielsen GP, Isaksson HJ, Finnbogason H, Gunnlaugsson GH. =Adenocarcinoma of the vermiform appendix: a population study. APMIS 1991;99:653-6.

3. Detky G. Cancer of the appendix arising from a villous adenoma. Orv Hetil 1983;124:2815-7.

4. Detky G. Carcinoma of the appendix arising on the basis of a mucinous cystadenoma. Zentralbl Allg Pathol 1985;130: 139-42.

5. Muller D. Appendiceal neoplasm resulting from a malignant transformation of a villous adenoma. Chirurg 1980;51:60910 .

6. Kinzler KW, Vogelstein B. Lessons from hereditary colorectal cancer. Cell 1996;87:159-70.

7. Marra G, Boland CR. Hereditary nonpolyposis colorectal cancer: the syndrome, the genes, and historical perspectives. J Natl Cancer Inst 1995;87:1114-25.

8. Perucho M. Microsatellite instability: the mutator that mutates the other mutator. Nat Med 1996;2:630-1.

9. Chung DC. The genetic basis of colorectal cancer: insights into critical pathways of tumorigenesis. Gastroenterology 2000;119:854-65.

10. Carr NJ, Arends MJ, Deans GT, Sobin LH. Tumors of the appendix. In: Hamilton SR, Aaltonen LA, eds. Pathology and 
genetics: tumors of the digestive system. Lyon, France: IARC Press; 2000. p. 93-102.

11. Moskaluk CA, Kern SE. Microdissection and polymerase chain reaction amplification of genomic DNA from histological tissue sections. Am J Pathol 1997;150:1547-52.

12. Boland CR, Thibodeau SN, Hamilton SR, et al. A National Cancer Institute Workshop on Microsatellite Instability for cancer detection and familial predisposition: development of international criteria for the determination of microsatellite instability in colorectal cancer. Cancer Res 1998;58:5248-57.

13. Baas IO, Mulder JW, Offerhaus GJ, Vogelstein B, Hamilton SR. An evaluation of six antibodies for immunohistochemistry of mutant p53 gene product in archival colorectal neoplasms. J Pathol 1994;172:5-12.

14. Caldas C, Hahn SA, Hruban RH, Redston MS, Yeo CJ, Kern SE. Detection of K-ras mutations in the stool of patients with pancreatic adenocarcinoma and pancreatic ductal hyperplasia. Cancer Res 1994;54:3568-73.

15. Kaplan EL, Meier P. Nonparametric estimation from incomplete observations. J Am Stat Assoc 1958;53:457-81.

16. Cuatrecasas M, Matias-Guiu X, Prat J. Synchronous mucinous tumors of the appendix and the ovary associated with pseudomyxoma peritonei: a clinicopathologic study of six cases with comparative analysis of c-Ki-ras mutations. Am J Surg Pathol 1996;20:739-46.

17. Szych C, Staebler A, Connolly DC, Wu R, Cho KR, Ronnett BM. Molecular genetic evidence supporting the clonality and appendiceal origin of pseudomyxoma peritonei in women. Am J Pathol 1999;154:1849-55.

18. Ramnani DM, Wistuba II, Behrens C, Gazdar AF, Sobin LH, Albores-Saavedra J. K-ras and p53 mutations in the pathogenesis of classical and goblet cell carcinoids of the appendix. Cancer 1999;86:14-21.

19. Paraskevakou H, Saetta A, Skandalis K, Tseleni S, Athanassiadis A, Davaris PS. Morphological-histochemical study of intestinal carcinoids and K-ras mutation analysis in appendiceal carcinoids. Pathol Oncol Res 1999;5:205-10.

20. O'Dowd G, Gosney JR. Absence of overexpression of p53 protein by intestinal carcinoid tumours. J Pathol 1995;175: 403-4.

21. Parker GM, Stollman NH, Rogers A. Adenomatous polyposis coli presenting as adenocarcinoma of the appendix. Am J Gastroenterol 1996;91:801-2.

22. Koorey D, Basha NJ, Tomaras C, Freiman J, Robson L, Smith A. Appendiceal carcinoma complicating adenomatous polyposis in a young woman with a de novo constitutional reciprocal translocation $\mathrm{t}(5 ; 8)(\mathrm{q} 22 ; \mathrm{p} 23.1)$. J Med Genet 2000; 37:71-5.

23. Ronnett BM, Shmookler BM, Diener-West M, Sugarbaker $\mathrm{PH}$, Kurman RJ. Immunohistochemical evidence supporting the appendiceal origin of pseudomyxoma peritonei in women. Int J Gynecol Pathol 1997;16:1-9.

24. Ronnett BM, Kurman RJ, Zahn CM, et al. Pseudomyxoma peritonei in women: a clinicopathologic analysis of 30 cases with emphasis on site of origin, prognosis, and relationship to ovarian mucinous tumors of low malignant potential. Hum Pathol 1995;26:509-24.

25. Carr NJ, Sobin LH. Unusual tumors of the appendix and pseudomyxoma peritonei. Semin Diagn Pathol 1996;13:31425.

26. Costa MJ. Pseudomyxoma peritonei: histologic predictors of patient survival. Arch Pathol Lab Med 1994;118:1215-9.
27. Davis G. Pseudomyxoma peritonei and the appendix. Med J Aust 1970;1:439-40.

28. Dejong $\mathrm{CH}$, Verhagen PF. Primary adenocarcinoma of the appendix and pseudomyxoma peritonei. Acta Chir Belg 1988;88:397-400.

29. Dejong CH, Booster MH, Theunissen PH, Beets GL, van Duin CJ. Pseudomyxoma peritonei. Ned Tijdschr Geneeskd 1997; 141:1196-8.

30. Elias D, Sabourin JC. Pseudomyxoma peritonei. A review [French]. J Chir (Paris) 1999;136:341-7.

31. Gough DB, Donohue JH, Schutt AJ, et al. Pseudomyxoma peritonei: long-term patient survival with an aggressive regional approach. Ann Surg 1994;219:112-9.

32. Hinson FL, Ambrose NS. Pseudomyxoma peritonei. Br J Surg 1998;85:1332-9.

33. Kahn MA, Demopoulos RI. Mucinous ovarian tumors with pseudomyxoma peritonei: a clinicopathological study. Int J Gynecol Pathol 1992;11:15-23.

34. Kurita M, Komatsu H, Hata Y, et al. Pseudomyxoma peritonei due to adenocarcinoma of the lung: case report. J Gastroenterol 1994;29:344-8.

35. Kusuyama T, Fujita M. Appendiceal mucinous cystadenoma associated with pseudomyxoma peritonei and multicystic peritoneal mesothelioma: report of a case. Surg Today 1995; 25:745-9.

36. Prayson RA, Hart WR, Petras RE. Pseudomyxoma peritonei: a clinicopathologic study of 19 cases with emphasis on site of origin and nature of associated ovarian tumors. Am J Surg Pathol 1994;18:591-603.

37. Sugarbaker PH. Pseudomyxoma peritonei. Cancer Treat Res 1996;81:105-19.

38. Wirtzfeld DA, Rodriguez-Bigas M, Weber T, Petrelli NJ. Disseminated peritoneal adenomucinosis: a critical review. Annu Surg Oncol 1999;6:797-801.

39. Lee KR, Scully RE. Mucinous tumors of the ovary: a clinicopathologic study of 196 borderline tumors (of intestinal type) and carcinomas, including an evaluation of 11 cases with pseudomyxoma peritonei. Am J Surg Pathol 2000;24:1447$64.7 /$

40. Yan H, Pestieau SR, Shmookler BM, Sugarbaker PH. Histopathologic analysis in 46 patients with pseudomyxoma peritonei syndrome: failure versus success with a secondlook operation. Mod Pathol 2001;14:164-71.

41. Smith JW, Kemeny N, Caldwell C, Banner P, Sigurdson E, Huvos A. Pseudomyxoma peritonei of appendiceal origin: the Memorial Sloan-Kettering Cancer Center experience. Cancer 1992;70:396-401.

42. Ronnett BM, Zahn CM, Kurman RJ, Kass ME, Sugarbaker PH, Shmookler BM. Disseminated peritoneal adenomucinosis and peritoneal mucinous carcinomatosis: a clinicopathological analysis of 109 cases with emphasis on distinguishing pathological features, site of origin, prognosis, and relationship to "pseudomyxoma peritonei" Am J Surg Pathol 1995; 19:1390-408.

43. Chuaqui RF, Zhengping Z, Emmert-Buck MR, Bryant BR, Nogales F, Tavassoli FA, et al. Genetic analysis of synchronous mucinous tumors of the ovary and appendix. Hum Pathol 1996;27:165-71.

44. Teixeira MR, Qvist H, Giercksky KE, Bøhler PJ, Heim S. Cytogenetic analysis of several pseudomyxoma peritonei lesions originating from a mucinous cystadenoma of the appendix. Cancer Genet Cytogenet 1997;93:157-9. 